\title{
Dynamic Properties of Footbridges: Influence of Asphalt Pavement and Support Conditions
}

\author{
Benedikt Weber ${ }^{1, a}$ \\ ${ }^{1}$ Empa - Swiss Federal Laboratories for Materials Science and Technology, Switzerland
}

\begin{abstract}
Natural frequencies and damping ratios are important parameters in the design of footbridges against vibrations. Although not normally considered in calculations, non-structural elements such as the asphalt pavement and the supports can have a significant influence on the dynamic properties. In this article we present results from vibration tests conducted on four footbridges over the last few years covering a wide range of asphalt temperatures. The experiments show that both the natural frequencies and the damping ratios can change significantly with temperature. In one particular case, a variation in natural frequency of $25 \%$ has been observed between high and low asphalt temperatures. An additional damping of around $1 \%$ due to the asphalt pavement has been detected. To more clearly understand the experimental results, the bridges were also analysed numerically using a visco-elastic material for the asphalt. The analysis of the experimental results also revealed that other non-structural elements can have a large influence on dynamic properties of bridges. In two cases, the supports did not perform as expected and lead to surprising results.
\end{abstract}

\section{Introduction}

The most important parameters in the design of footbridges against vibration problems are the natural frequencies and damping ratios. Although determining these properties seems to be a simple standard task, calculated frequencies as well as estimated damping values are often not realistic if the influence of nonstructural elements is not considered. In particular, the asphalt pavement and the supports can have a significant influence on the dynamic properties of footbridges. Including these effects is important for interpreting experimental results or for the design.

Literature on the influence of asphalt pavement on dynamic properties is scarce. Hamm [1] reports damping values from experiments on several timber bridges and recommends to add $0.3 \%$ to take into account the asphalt. Gülzow and coworkers [2] performed dynamic field tests on a timber bridge without and with asphalt pavement. With asphalt, they observed a decrease in frequency due to the additional mass and an increase in damping. Schubert and coworkers [3] performed vibration tests on two laboratory timber bridges at room temperature. By comparing the results with finite element calculations, the authors show that the asphalt stiffness contributes significantly to the overall stiffness. This was not necessarily expected since the asphalt was separated from the timber deck by a glass fiber tissue. Their calculations also show that a large variation in frequency can be expected for a temperature range from $0^{\circ} \mathrm{C}$ to $40^{\circ} \mathrm{C}$.
Ralbovsky and coworkers [4] describe a one-year monitoring program of an ultra-high performance concrete arch bridge. They observed a clear dependency of natural frequencies and damping ratios on the temperature similarly to what will be presented in this paper.

In this article we present results from dynamic experiments conducted on four footbridges in the last few years with the goal to analyse the influence of the asphalt temperature on the dynamic properties. To cover the full range of temperatures, tests were conducted on several days distributed over the seasons of the year. For three of the bridges, tests were also performed before the pavement was applied. The in-depth analysis of these results together with numerical simulations makes it possible to better understand the influence of asphalt temperature in different situations.

The analysis of the experimental results also revealed that other non-structural elements can have a large influence on the dynamic properties. In one case, the high friction in the bearings increased the frequency and the damping drastically. In another case, the dynamic stiffness of elastomer bearings differed by a factor of 10 from the static value provided by the manufacturer.

In Section 2, we briefly describe the general test procedure and in Section 3, the asphalt behaviour is discussed. The dynamic behaviour of four bridges with respect to asphalt temperature is presented in Section 4. Section 5 then discusses two bridges with a large influence of the supports.

\footnotetext{
a Corresponding author: Benedikt.Weber@empa.ch
} 


\section{Experimental procedure}

Vibration tests were performed using an electromagnetic shaker (Figure 1a) and several high-sensitivity accelerometers oriented in vertical and in horizontal direction (Figure 1b). In a first stage, the bridge was excited with a band-limited random force. Looking at the power spectrum, an overview of natural frequencies was obtained on site during the tests. Then a harmonic force was applied at each frequency of interest. Stopping the force abruptly yielded a decay curve for determining the natural frequency and damping ratio at amplitudes comparable to the serviceability level. Tests were performed on hot and cold days during the year and several measurements were carried out during each day, covering a wide range of temperatures.

Mode shapes were determined from the response due to broad-band excitation using the N4SID algorithm implemented in MATLAB $\AA$. These mode shapes were mainly used for identifying the modes when comparing with numerical models. The procedure also yields natural frequencies and damping values for low excitation levels. These values are generally less reliable but were in many cases very similar to the ones obtained from the decay curves.
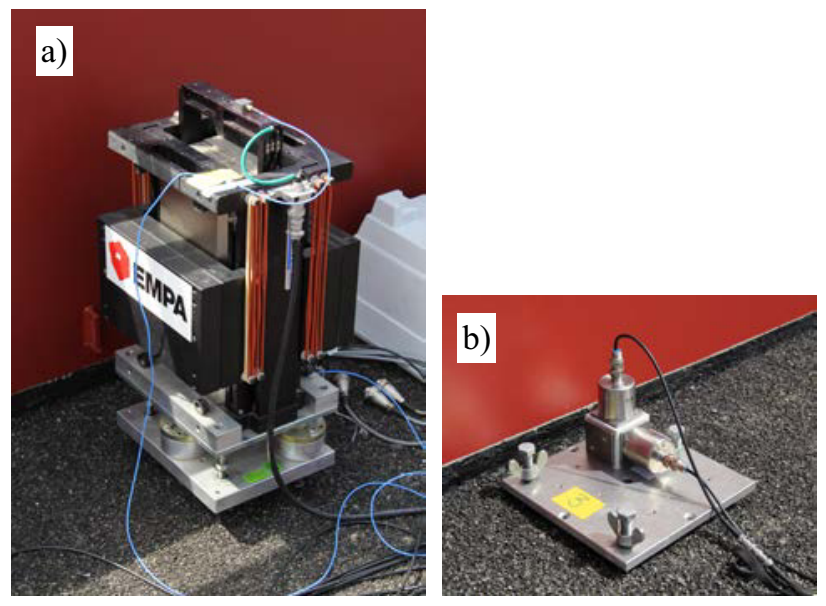

Figure 1. (a) Electromagnetic Shaker and, (b) plate with two accelerometers in two directions.

\section{Asphalt}

\subsection{Overview}

Since a main aspect of this investigation was the influence of the asphalt pavement at different temperatures, we dedicate an own section to the behaviour and modelling of this material. Mastic asphalt with similar properties was used in all cases described here. Due to its high content of binder, mastic asphalt is almost liquid when heated to $200^{\circ} \mathrm{C}$ and can be placed manually without heavy equipment (Figure 2). To reduce cooling time, mastic asphalt is usually placed in layers of 25-30 mm.

Since the main goal of the research was to determine the vibration behaviour at different temperatures of the asphalt pavement, thermo-elements (type K) were

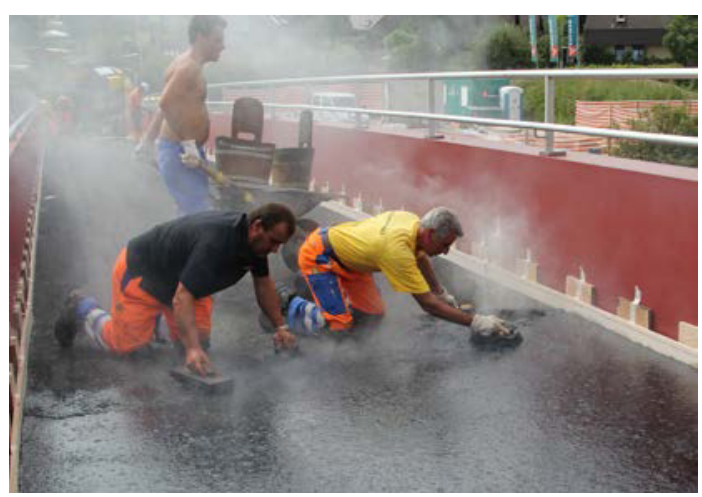

Figure 2. Placement of mastic asphalt.

embedded in the pavement. This was done for two bridges, one newly constructed and one newly paved during rehabilitation. For two other bridges, we could not get the permission from the owner to embed sensors, and only surface temperatures were measured. The two bridges instrumented with thermo-elements were steel bridges with two asphalt layers. The thermo-elements were mounted between the steel deck and the first asphalt layer, and between the two asphalt layers. For backup reasons, the elements were mounted in pairs (Figure 3a). During the vibrations tests, a thermo-element was also placed on the upper surface of the pavement (Figure $3 b$ ). The sensors were positioned at the centre of the crosssection and the cables with the sockets were leaving the pavement at the side of the bridge (Figure 3c). A weighted mean (centre with double weight) was taken as the reference temperature. Two sets of sensors were mounted along the length of the bridges to see the effect of different exposure to sunlight.

A typical evolution of temperature during a day is plotted in Figure 4. The considered bridge is oriented north-south and surrounded by trees. It received full sunlight just before noon until $15 \mathrm{~h}$, a fact which is clearly visible in the surface temperature. Due sun radiation, the temperature went up almost $50^{\circ} \mathrm{C}$. Due to the large temperature variation, several vibration experiments could be performed within one day, covering a large temperature range.
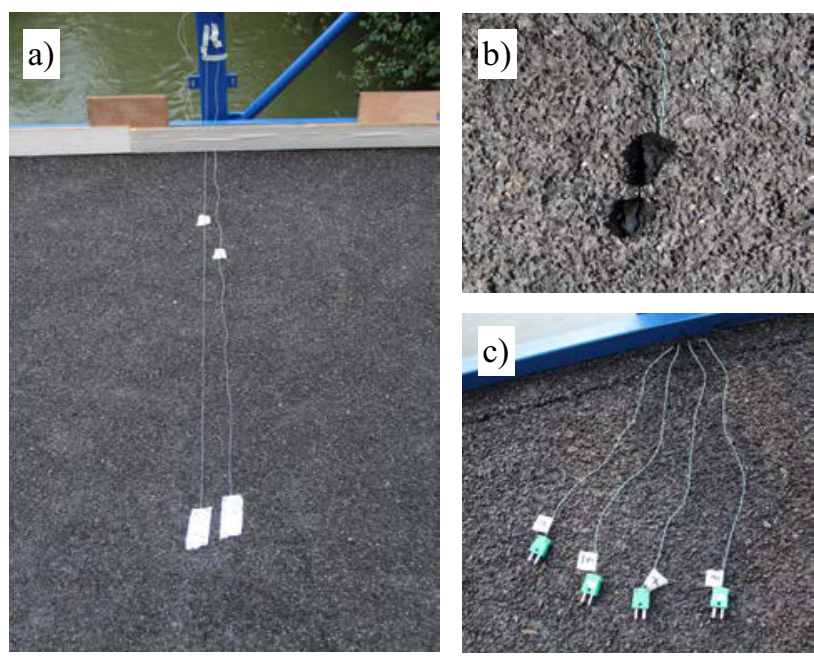

Figure 3. Thermo-elements (a) installed before asphalting and (b) installed on surface, (c) cable ends with sockets. 


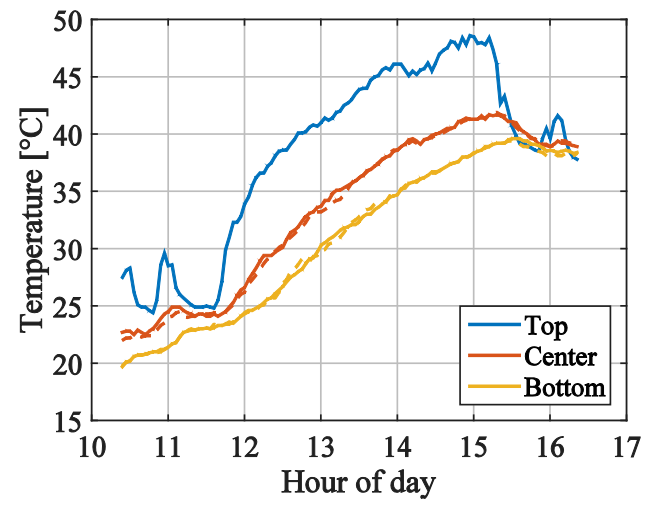

Figure 4. Measured temperature evolution in asphalt layer.

\subsection{Material properties and numerical model}

In order to interpret the measurements, all tested bridges were also modelled by finite elements. While standard procedures were used for modelling the structures, the treatment of asphalt deserves some more detailed explanation.

Asphalt is modelled as a visco-elastic material. Typically, the shear modulus and the phase angle are measured for several frequencies and temperatures. This results in a complex shear modulus $G^{*}$ whose real and imaginary part are the storage modulus $G^{\prime}$ and the loss modulus $G^{\prime \prime}$, respectively:

$$
G^{*}=G^{\prime}+\mathrm{i} G^{\prime \prime}=G^{\prime \prime}(1+\mathrm{i} \eta)
$$

The storage modulus is related to the stiffness, while the loss modulus is related to the damping of the material. The loss modulus is often expressed as a loss factor $\eta$.

The storage modulus is plotted in Figure 5. In the temperature range of interest, it decreases by two decades with increasing temperature. The dependency on frequency, on the other hand, is by far less important. The loss factor is shown in Figure 6. This value increases with increasing temperatures, although the variation is less pronounced than for the storage modulus.

To calculate Young's modulus, Poisson's ratio $v$ is also needed. However, data for this quantity are difficult to obtain experimentally and not readily available from the literature. Di Benedetto and coworkers [5] have shown experimentally that Poisson's ratio is not a constant but varies from 0.35 for low temperatures (high frequencies) to 0.5 for high temperatures (low

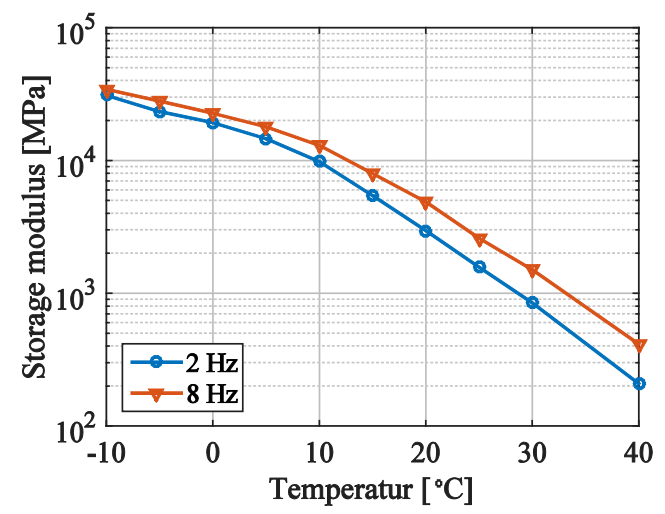

Figure 5. Storage modulus in function of temperature.

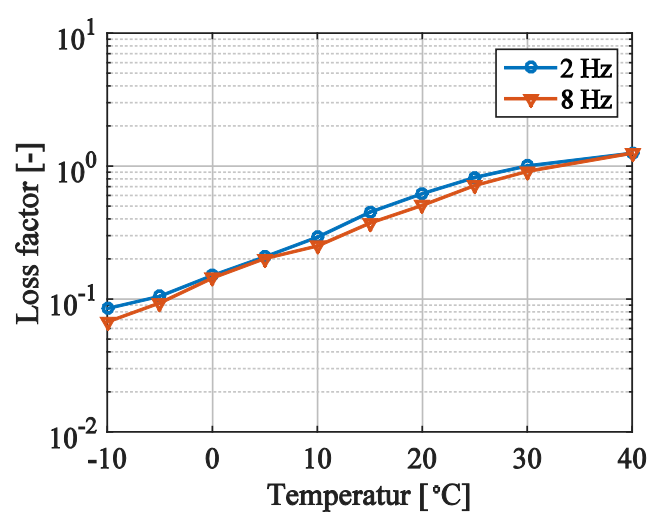

Figure 6. Loss factor in function of temperature.

frequencies). The phase angle is very small $\left(2^{\circ}\right)$ and is neglected in our material model. The value of $v=0.5$ indicates that the material behaves like a fluid at high temperatures. This behaviour is best described by a bulk modulus. It turns out that a constant bulk modulus is a very good approximation to the model of Di Benedetti and coworkers [5]. Fitting the model to the measured shear modulus yields a bulk modulus of $K^{\prime}=2 \times 10^{5} \mathrm{MPa}$. Poisson's ratio can then be calculated by

$$
v=\frac{3 K^{\prime}-2 G^{\prime}}{2\left(3 K^{\prime}+G^{\prime}\right)}
$$

Using the above value with the measured storage modulus results in the Poisson's ratio plotted in Figure 7. For high temperatures (low frequencies) the shear modulus becomes small and Poisson's ratio approaches the value of 0.5 .

The bulk modulus used in Equation (2) is a storage modulus. For the complex modulus, we consider the relationship:

$$
K^{*}=\frac{2 G^{*}(1+v)}{3(1-2 v)}
$$

Since Poisson's ratio is taken to be real, the loss factor measured for shear is also applicable to the bulk modulus:

$$
K^{*}=K^{\prime}(1+\mathrm{i} \eta)
$$

For the finite element analysis we used a program (COMSOL Multiphysics) that solves the complex eigenvalue problem. Damping is introduced by an isotropic loss factor. This means that the real-valued

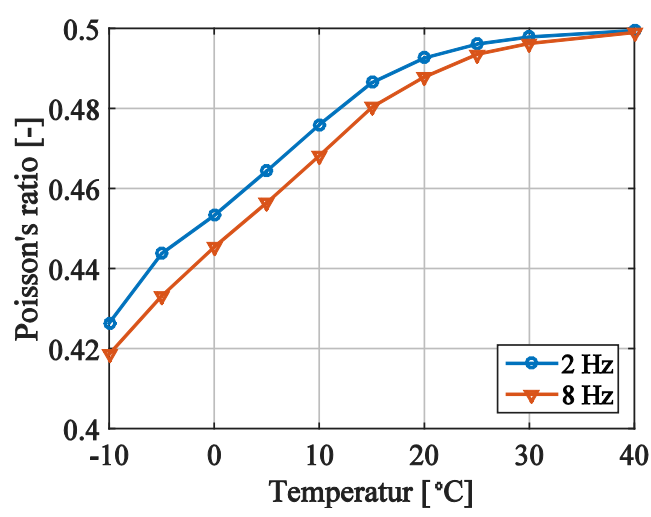

Figure 7. Poisson's ratio in function of temperature. 
element stiffness matrices are multiplied by the complex factor $(1+\mathrm{i} \eta)$ before being assembled. The same factor is applied for shear strains and for volumetric strains. For the structural materials (steel, timber), a constant loss factor was used, using the relationship

$$
\eta=2 \zeta
$$

where $\zeta$ is the damping ratio. A damping ratio of $0.3 \%$ has been taken for the steel bridges and $2 \%$ for the timber bridge. Note that the commonly employed Rayleigh damping for structures is not suitable here, since this would cause a change in damping by merely changing the frequency of the structure. But then, we cannot associate different loss factors for different modes.

Since the system matrices are complex, the eigenvalue calculation will yield complex eigenvalues, which can be interpreted in terms of frequency and damping in the following way:

$$
\lambda_{n}=-\zeta_{n} \omega_{n} \pm \mathrm{i} \omega_{n} \sqrt{1-\zeta_{n}^{2}}
$$

Natural frequencies and damping ratios can thus be extracted as

$$
f_{n}=\frac{1}{2 \pi}\left|\lambda_{n}\right| \text { and } \zeta_{n}=\frac{-\operatorname{Re}\left(\lambda_{n}\right)}{\left|\lambda_{n}\right|}
$$

Note that the calculations were performed for different temperatures using the asphalt properties for each temperature. However, the dependency of the asphalt properties on frequency was not taken into account. Rather, the frequency determining the asphalt properties was selected a priori. This approximation is justified by the fact that the material properties do not change much with frequency in the range of interest.

\section{Dynamic properties of four bridges}

\subsection{Steel truss bridge}

This bridge is a steel truss bridge with $17.2 \mathrm{~m}$ span and $3.6 \mathrm{~m}$ width (Figure 8). The two trusses act as railings and are connected by lateral beams every $1.325 \mathrm{~m}$. The deck lying on these lateral beams consists of a $20 \mathrm{~mm}$ thick steel plate with longitudinal stiffeners (Figure 9). The cross-section is sketched in Figure 10. The asphalt pavement consists of two layers with a total thickness of $6 \mathrm{~cm}$. The bridge is supported on four elastomer bearings.

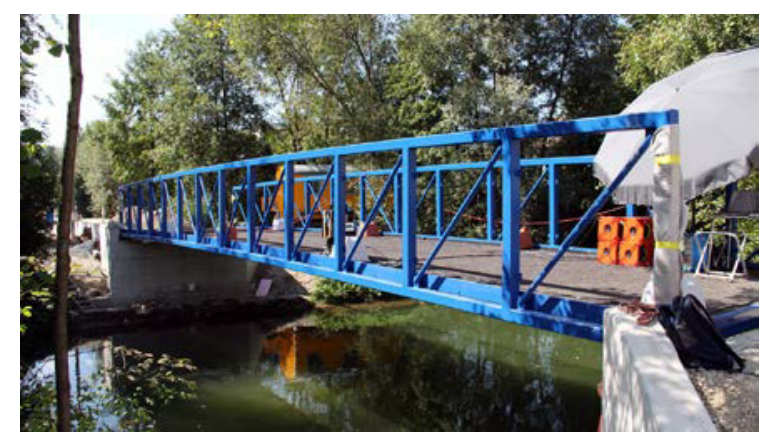

Figure 8. Steel truss bridge: overview.

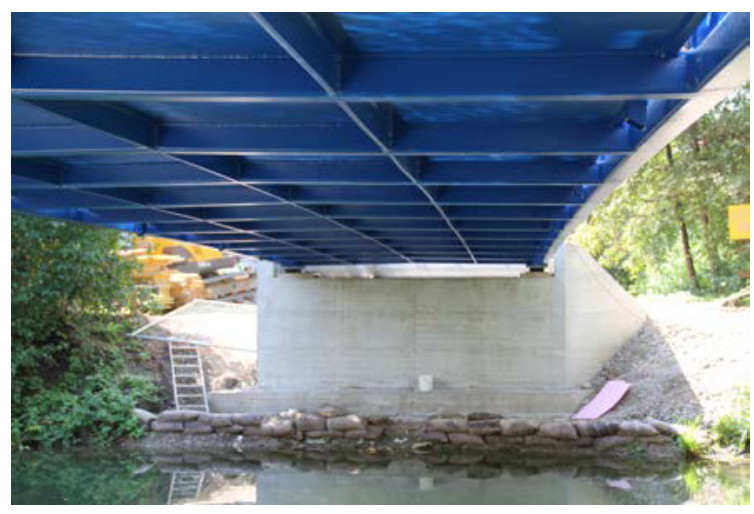

Figure 9. Steel truss bridge: view from below.

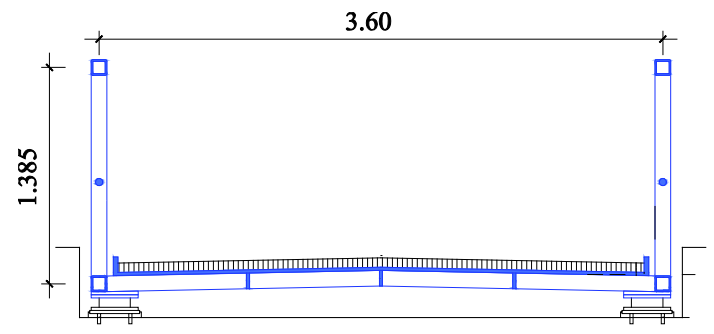

Figure 10. Steel truss bridge: cross-section

The first three modes (two bending and one torsion mode) are shown in Figure 11. The identified mode shapes are shown on the left, while the calculated mode shapes are presented on the right. Note that the bridge does not behave like a beam. Rather, the deck deforms as a plate supported on both trusses. The asphalt thus influences both the longitudinal and the transverse bending. This made modelling and experimental identification rather difficult, especially for higher modes. It happened, for instance, that some modes could only be identified at certain temperatures.
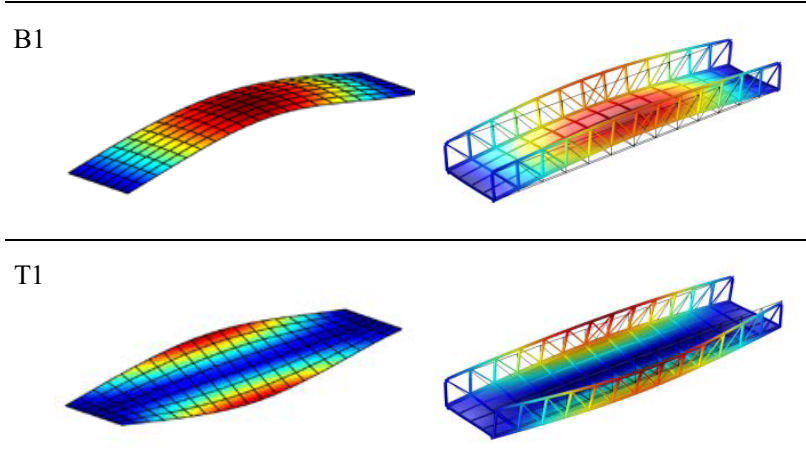

B2

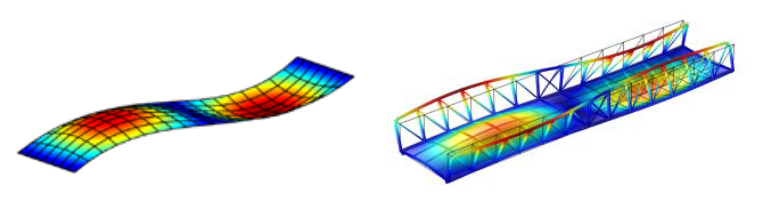

Figure 11. Mode shapes of steel truss bridge: comparison of experimental (left) and numerical (right) mode shapes. 

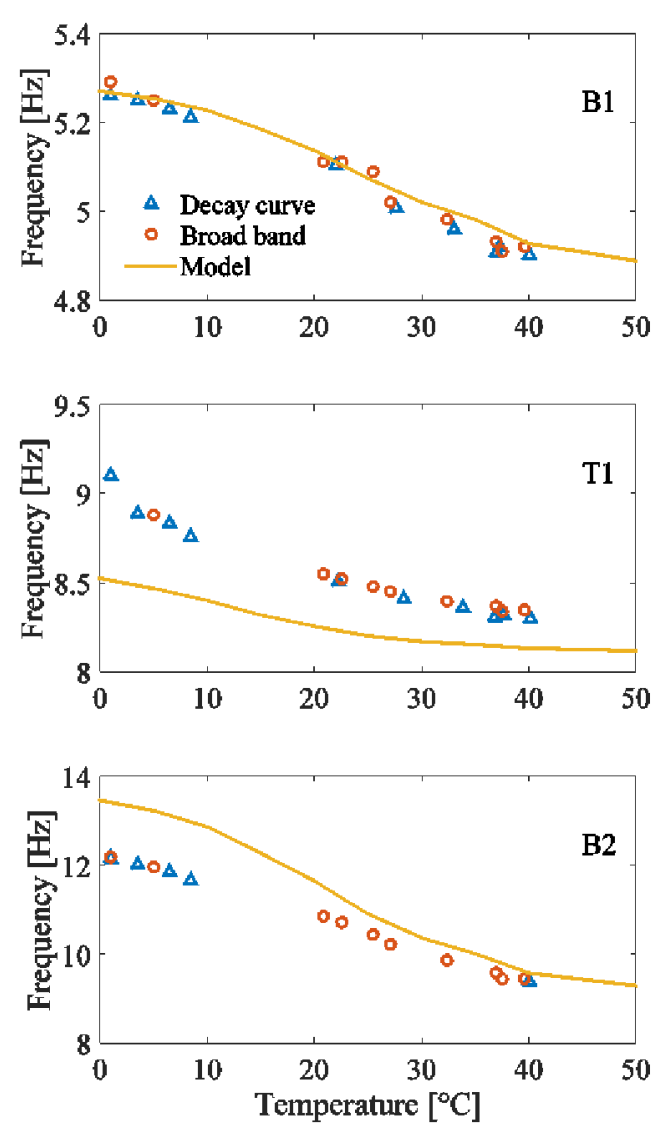

Figure 12. Natural frequencies for steel truss bridge in function of asphalt temperature.
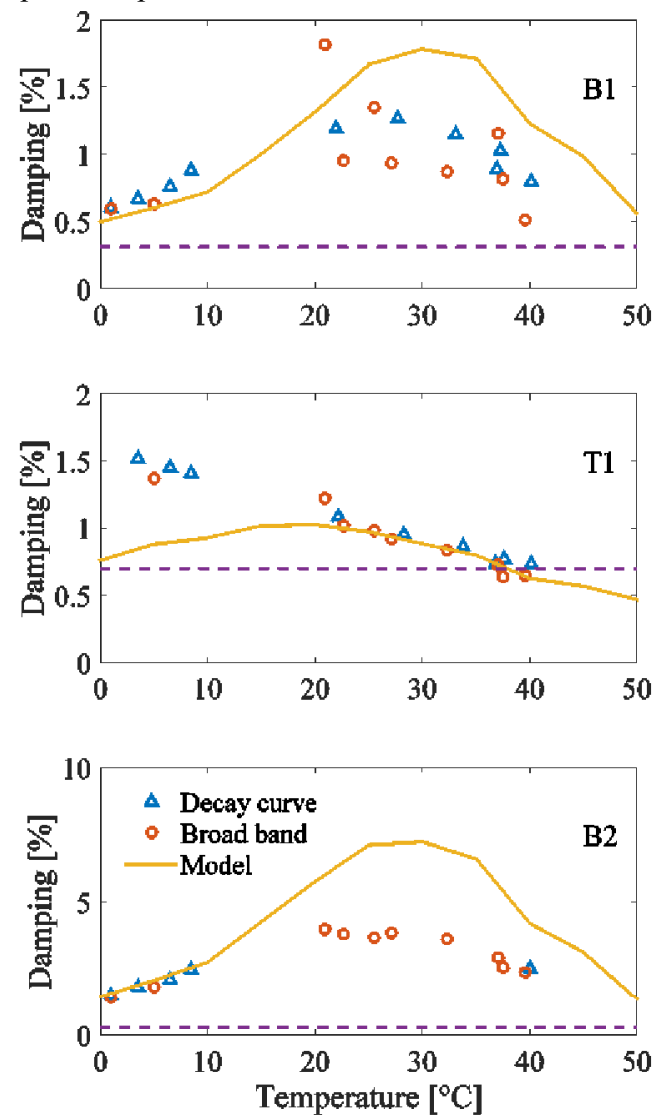

Figure 13. Damping ratios for steel truss bridge in function of asphalt temperature. The dashed horizontal lines indicate the measured damping without asphalt.
The natural frequencies and the corresponding damping ratios are shown in Figures 12 and 13 as functions of the asphalt temperature (mean value over thickness). The natural frequencies (Figure 12) decrease monotonically with increasing temperature, whereas the damping ratios (Figure 13) first increase up to $20^{\circ} \mathrm{C}$ and then decrease again. The pattern for the damping ratio is somewhat unexpected at first sight, but is typical, as will be shown for other bridges. As mentioned before, measured frequencies and damping ratios were determined from both, broad band excitation and decay curves as indicated in the figures. Both methods give consistent results in this case. Broad band results are useful in cases where the modes could not be identified on site and no decay curves are available. The measured dynamic properties are well captured by the finite element calculations, confirming that the variations indeed result from the temperature-dependent asphalt properties. The dashed horizontal lines in Figure 13 indicate the measured damping ratios without asphalt. Nevertheless, an overall value of $0.3 \%$ has been used in the finite element model.

\subsection{Timber bridge}

The second bridge is the timber bridge shown in Figure 14. The bridge has three spans with a main span of $22 \mathrm{~m}$ and two side spans of $18 \mathrm{~m}$ (Figure 15, elevation). It consists of three girders, which are connected by hinges. The hinges are placed in such a way that the bridge acts like a continuous beam for static loading (Gerber beam). The girders consist of four glue-laminated timber beams with a cross-laminated timber plate on top (Figure 15, cross-section). The plate is covered by a layer of mastic asphalt of $3.5 \mathrm{~cm}$ thickness.

The calculated mode shapes of the first thee bending modes are shown in Figure 16. In the first and third mode, the bridge behaves like a continuous beam, while in the second mode, the hinges are clearly visible.

The measured frequencies and damping ratios are shown in Figures 17 and 18. This bridge is extremely sensitive to temperature changes. At warm temperatures where the asphalt does not contribute to the stiffness, the fundamental frequency is $3.2 \mathrm{~Hz}$. This values increases for cold temperatures to almost $4 \mathrm{~Hz}$, which is an increase of $25 \%$. The measured damping values follow again the typical pattern with a maximum around $20^{\circ} \mathrm{C}$.

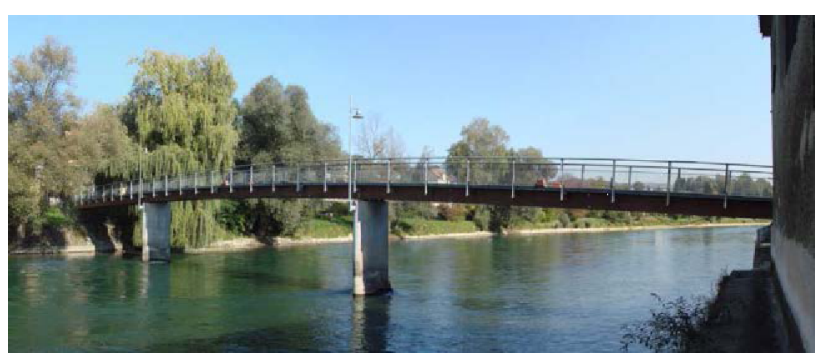

Figure 14. Timber bridge. 


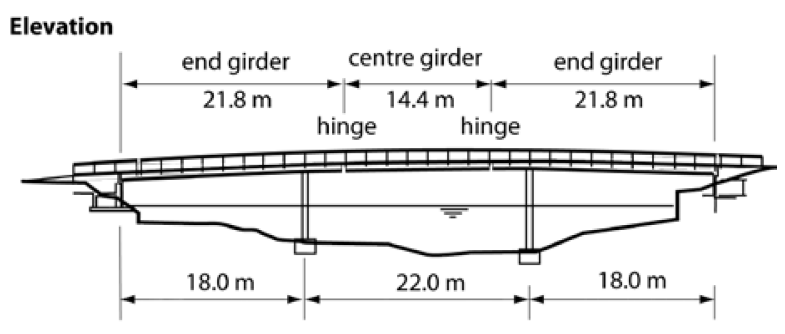

\section{Cross-section}

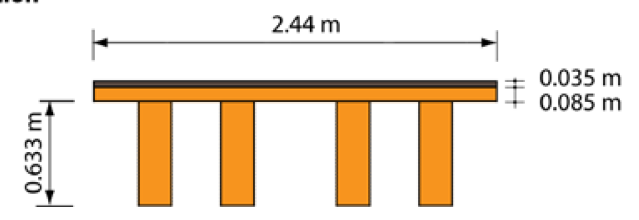

Figure 15. Timber bridge: elevation and cross-section.
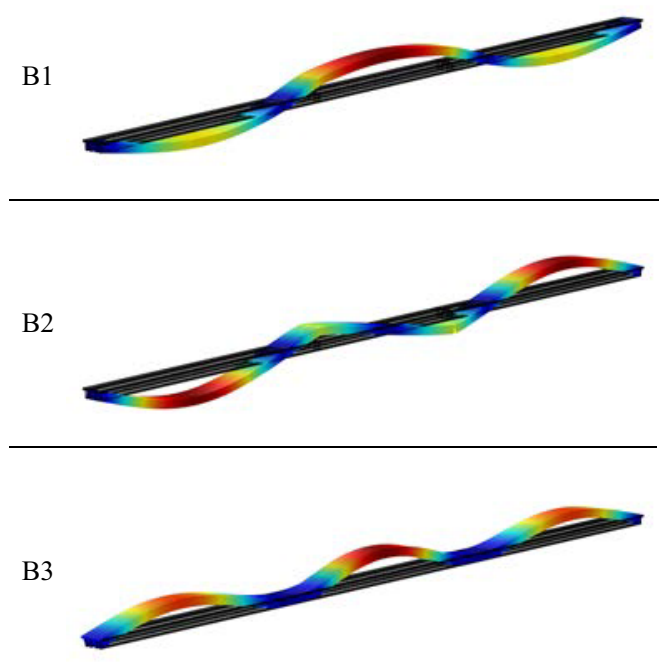

Figure 16. Timber bridge: first three bending mode shapes from finite element model.

The numerical model with full bond between the timber plate and the asphalt pavement overestimates the influence of the asphalt stiffness at low temperatures. Therefore an elastic interface between the structure and the asphalt layer was introduced. This interface represents the partial bond resulting from a separation layer of glass fiber tissue, typically placed between timber and asphalt to allow vapor to escape as the hot asphalt is applied. The value of the interface stiffness was found by calibration. However, a single parameter improves frequencies and damping ratios of all modes at the same time and yields an excellent agreement with experimental values. An attempt to quantify the interface stiffness experimentally was also made employing an apparatus proposed by Ascher [6]. While the existence of a flexible layer has been demonstrated, the value measured on a cylinder with $100 \mathrm{~mm}$ diameter was considerably larger than the calibration value found from the numerical model.
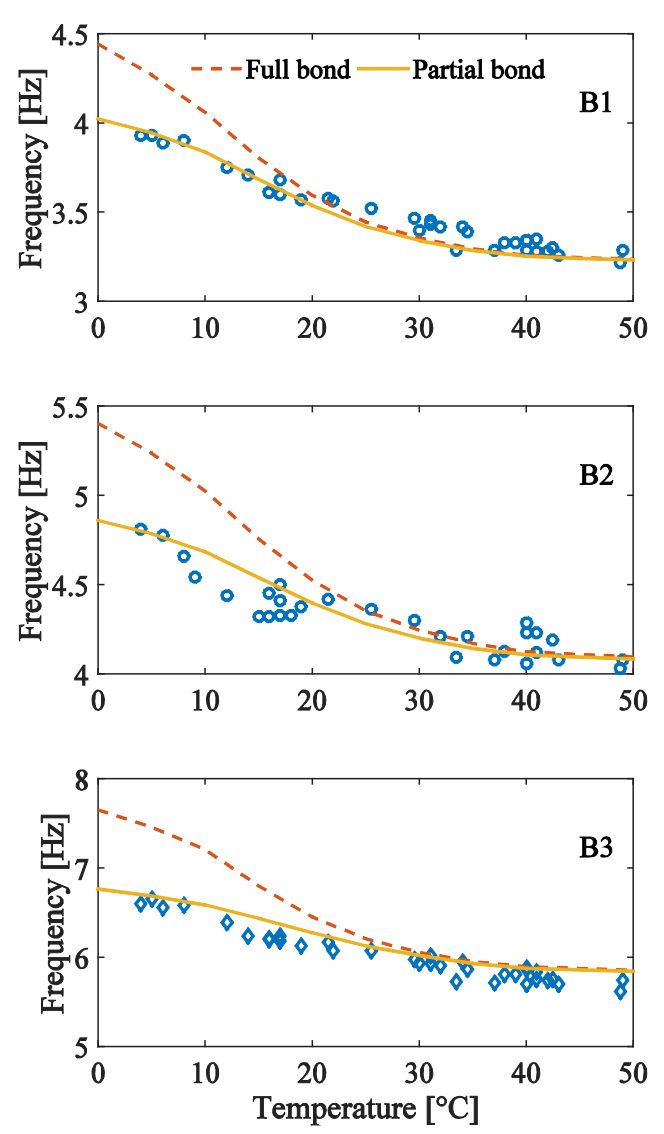

Figure 17. Natural frequencies for timber bridge in function of asphalt temperature.
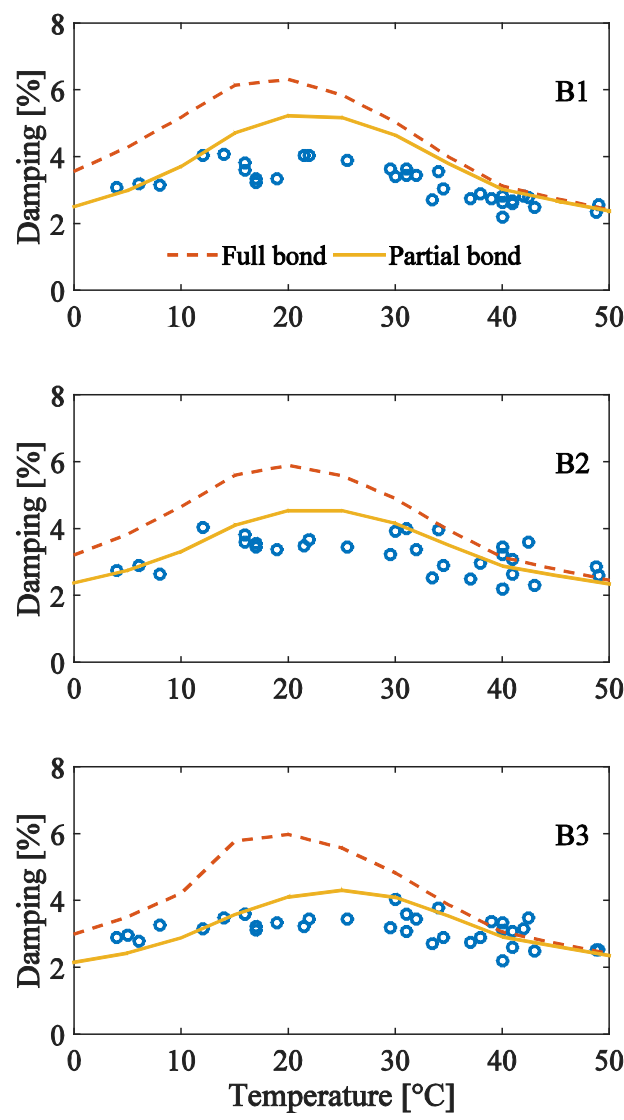

Figure 18. Damping ratios for timber bridge in function of asphalt temperature. 


\subsection{Cable-stayed bridge}

The next bridge is a cable-stayed steel bridge with a main span of $45 \mathrm{~m}$ and a width of $3.1 \mathrm{~m}$ (Figure 19). Originally it had no pavement but only a coating. In the course of rehabilitation, a $5 \mathrm{~cm}$ thick asphalt pavement has been applied. The cross-section is shown in Figure 20. A special point is that the bridge is equipped with a tuned mass damper (TMD). The added mass and the variable stiffness of the asphalt pavement can potentially detune the damper and reduce its effectiveness.

The mode shapes of the first three bending modes are shown in Figure 21. The experimentally determined mode shapes agree well with the numerical results. Only the deck was measured, but not the cables and the pylon.

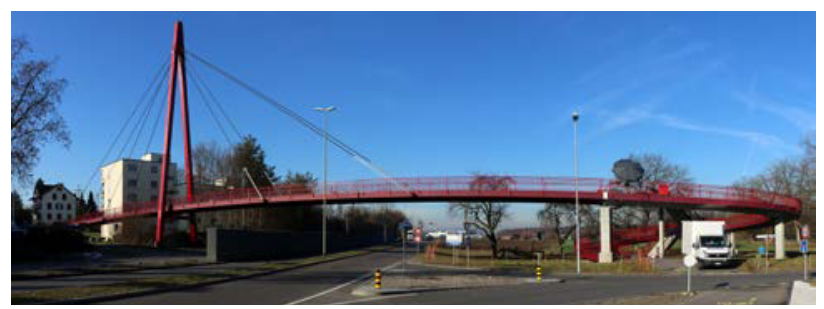

Figure 19. Cable-stayed bridge.

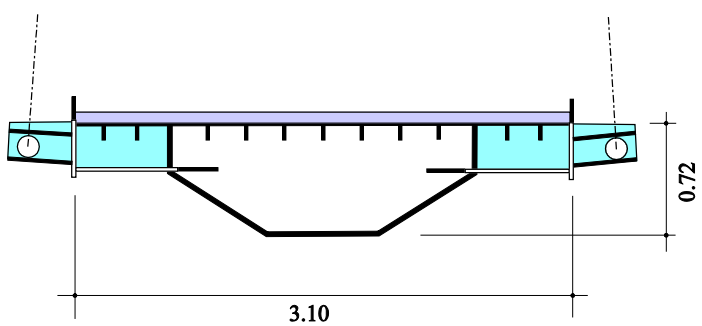

Figure 20. Cable-stayed bridge: cross-section.

B1
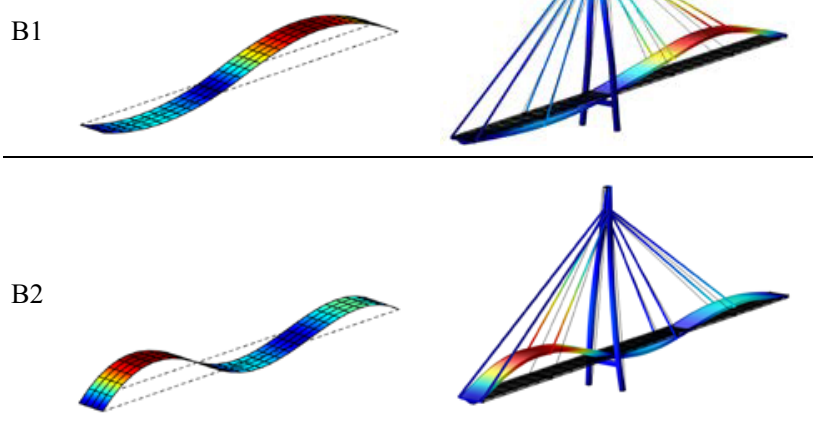

B3
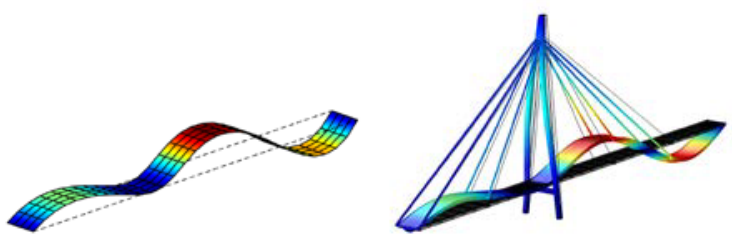

Figure 21. Mode shapes of the cable-stayed bridge: comparison of experimental (left) and numerical (right) mode shapes.
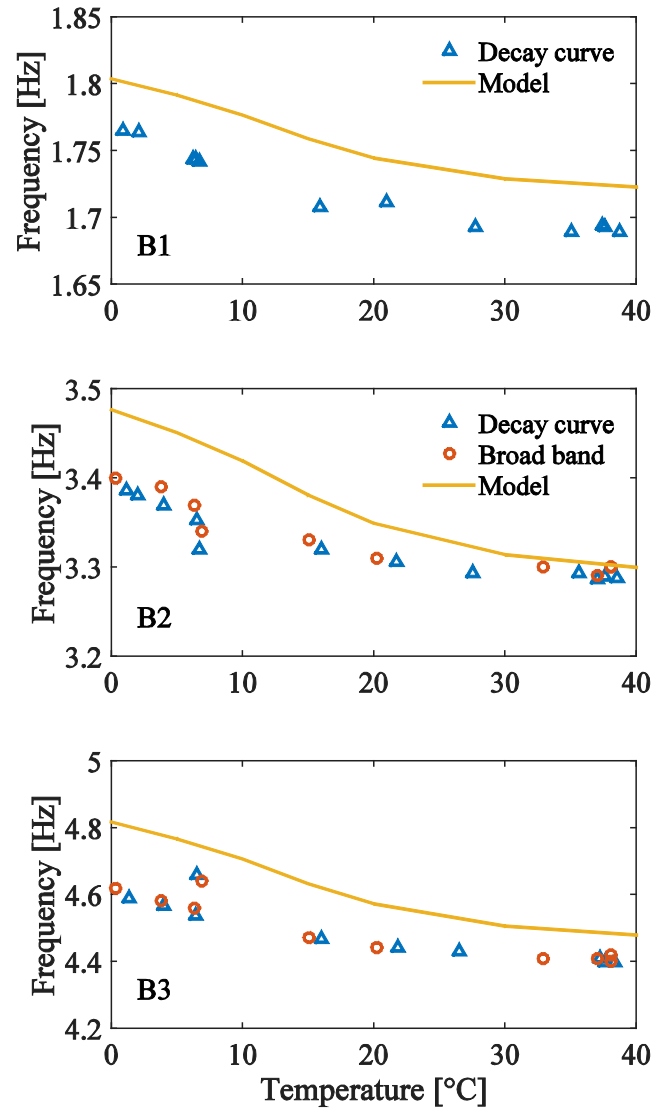

Figure 22. Natural frequencies for cable-stayed bridge in function of asphalt temperature.
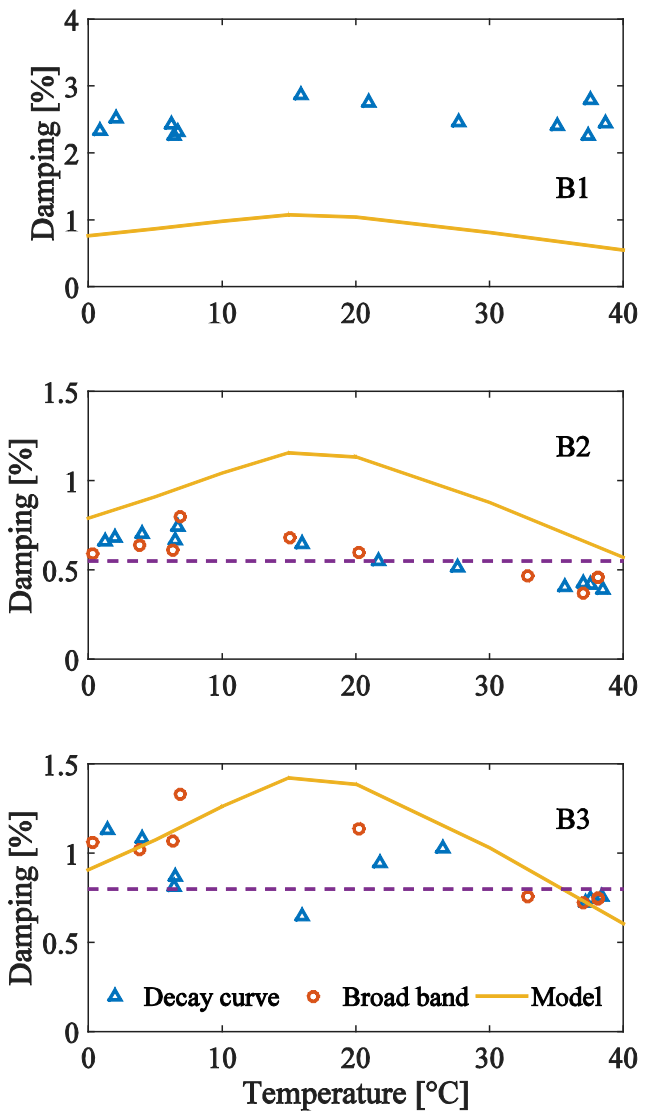

Figure 23. Damping ratios for cable-stayed bridge in function of asphalt temperature. The dashed lines show the damping ratios without the asphalt pavement. 
The influence of the asphalt temperature on the dynamic properties is shown in Figures 22 and 23. The variation in frequency (Figure 22) is small since a large part of the stiffness is provided by the stay cables and the relative influence of the asphalt is, therefore, limited. Damping ratios (Figure 23) also show a small variation. The high damping values in the first mode (around 2.5\%) are due to the TMD. The dynamic behaviour of the TMD has not been in included in the finite element model, only its mass. The measurements show that the TMD is still working properly, albeit not with full efficiency. The damping of mode B3 shows a large scatter, probably due to the vibration of the cables. The dashed lines in modes B2 and B3 show the damping ratios without the asphalt pavement. Nevertheless, an overall value of $0.3 \%$ has been used in the finite element model.

\subsection{Box girder steel bridge}

The final bridge presented is a box girder steel bridge with a length of $42 \mathrm{~m}$ and a width of $4 \mathrm{~m}$ (Figure 24). The cross-section is shown in Figure 25. The asphalt pavement has a thickness of $7.5 \mathrm{~cm}$, which is unusually high for this kind of bridge. For this bridge, vibration tests were done on a cool and on a warm day. Asphalt temperatures were not directly measured, since the owner did not give the permission to embed thermo-elements. Instead, a $40 \times 40 \mathrm{~cm}^{2}$ specimen with the same pavement strucutre (steel plate and 3 asphalt layers) was used as a reference. However, it turned out that the surface temperature of the specimen was 5 to $10^{\circ} \mathrm{C}$ higher than the surface temperature of the bridge pavement. The temperature measurements could thus not be used directly. Estimated values are around $10^{\circ} \mathrm{C}(\mathrm{cool})$ and $30^{\circ} \mathrm{C}$ (warm) for the two vibration tests. For this bridge, the influence of temperature was relatively low, as can be seen from Table 1. For this reason, measurements were not extended to the whole temperature range.

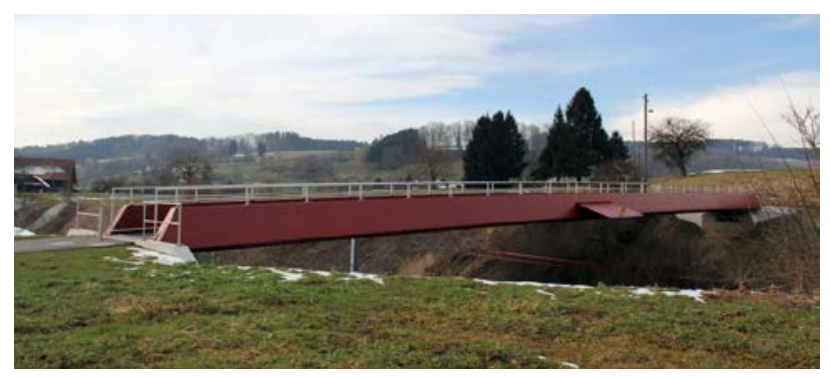

Figure 24. Box girder bridge.

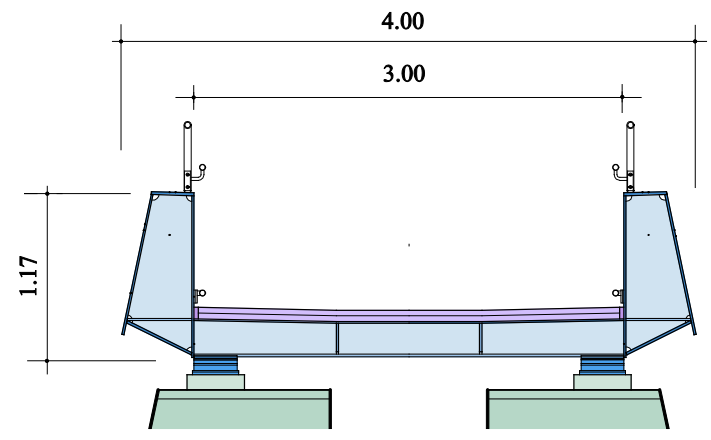

Figure 25. Box girder bridge: cross-section.
Table 1. Measured natural frequencies and damping ratios.

\begin{tabular}{llllll}
\hline \multicolumn{2}{l}{ Temperature } & Cool & \multicolumn{3}{l}{ Warm } \\
\hline Mode & Typ & $\begin{array}{l}\text { Freq. } \\
{[\mathrm{Hz}]}\end{array}$ & $\begin{array}{l}\text { Damp. } \\
{[\%]}\end{array}$ & $\begin{array}{l}\text { Freq. } \\
{[\mathrm{Hz}]}\end{array}$ & $\begin{array}{l}\text { Damp } \\
{[\%]}\end{array}$ \\
\hline B1 & Bending & 1.89 & 1.69 & 1.82 & 1.98 \\
\hline T1 & Torsion & 4.06 & 1.26 & 3.91 & 1.25 \\
\hline B2 & Bending & 5.40 & 0.47 & 5.34 & 0.32 \\
\hline
\end{tabular}

The reason for the small influence of the asphalt pavement on the natural frequencies is the cross-section of this bridge: the pavement is near the neutral axis and undergoes only small strains (Figure 25).

To get a more complete picture, results from a finite element simulation are provided in the following. Natural frequencies are shown in Figure 26. The measured frequency values are confirmed. Damping ratios are given in Figure 27. Except for the second bending mode, the numerical values differ considerably from the measured values. As will be discussed in Section 5.1, friction in the bearings adds substantially to the overall damping of this bridge, but is not included in the model. The model suggests the typical form of the damping ratios with a maximum around $20^{\circ} \mathrm{C}$. However, too few measurements have been performed to confirm this pattern. Interestingly enough, the torsion mode (T1) shows a considerable influence of the asphalt on the damping. The argument that the pavement is near the neutral axis only holds for bending; the asphalt is nevertheless activated in torsion.

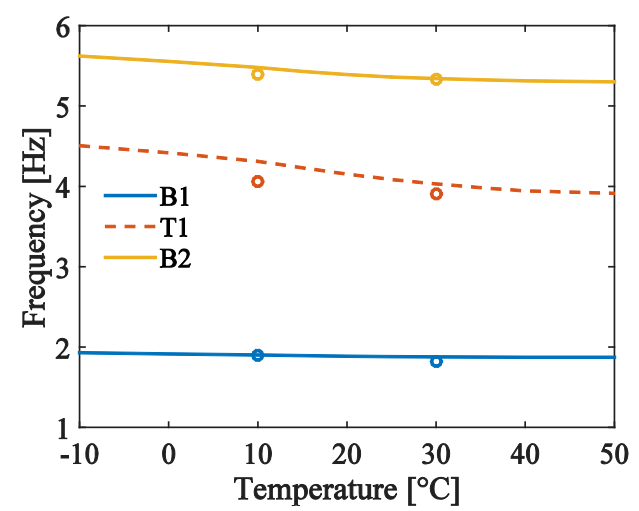

Figure 26. Natural frequencies for box girder bridge in function of asphalt temperature.

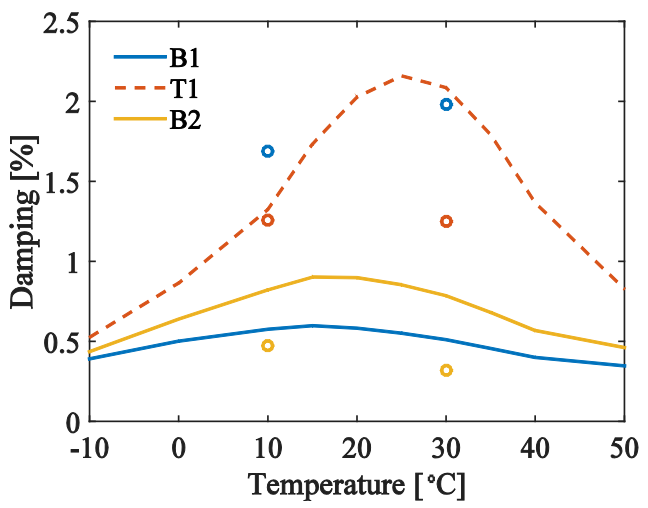

Figure 27. Damping ratios for box girder bridge in function of asphalt temperature. 


\subsection{Comparison and analysis}

Although very similar asphalts were used for all bridges, the effect of temperature is not the same in all cases. In order to get a better overview, the fundamental frequencies of all four bridges are compared in Figure 24. The plot shows the relative frequencies

$$
\varphi(T)=f_{c}(T) / f_{s}
$$

obtained by normalizing the calculated frequencies of the composite structure $f_{c}$ with the frequencies $f_{s}$ of the structure without asphalt stiffness. For high temperatures, the asphalt is weak and gives practically no contribution to the stiffness. The relative frequencies approach 1.0 in this case. For colder temperatures, the asphalt stiffness increases and the fundamental frequencies increase depending on the cross-section. The largest effect has been observed for the timber bridge, where the pavement is situated at the upper edge of the cross-section. The second largest effect is observed in the truss bridge. The cable-stayed bridge shows only a small increase, although the pavement is at the upper edge. The reason is that a large part of the stiffness is not provided by bending of the beam but by the cables. This part is not influenced by temperature. The least effect is seen for the box girder bridge where the pavement is close to the neutral axis of the cross-section.

To better understand the damping behaviour, we look at a composite beam section. The bending stiffness of the composite section is

$$
B_{c}=E_{s} I_{s}+E_{a}^{\prime} I_{a}+E_{a}^{\prime} A_{a} \beta h^{2}
$$

where $E$ denotes the Young's modulus (storage modulus $E^{\prime}$ for asphalt), $I$ the moment of inertia, and $A$ the area. The index $c$ refers to the composite section, $s$ to the structure, and $a$ to the asphalt pavement. The distance between the centroids of the structure and the pavement is denoted by $h$. The factor $\beta$ takes care of the shift of the neutral axis of the composite section relative to the section of the structure without pavement. This factor can be shown to be

$$
\beta=\frac{1}{1+E_{a}^{\prime} A_{a} / E_{s} A_{s}}
$$

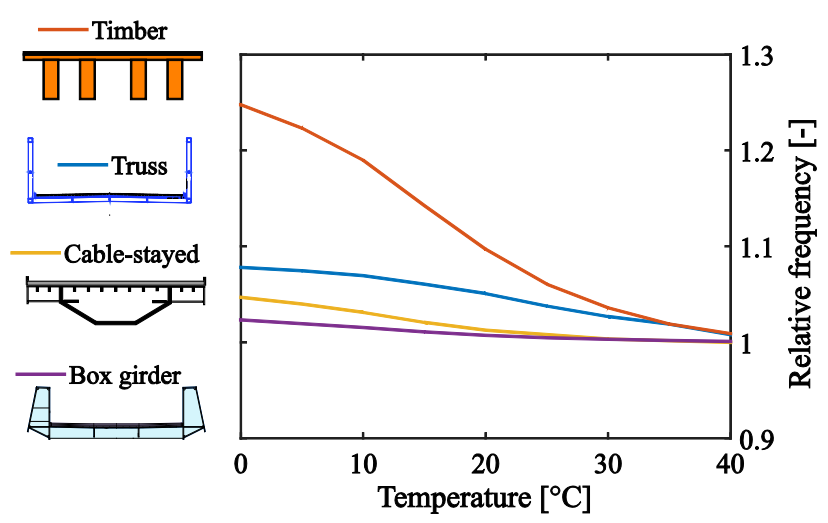

Figure 24. Comparison of relative fundamental frequencies of different bridges in function of the asphalt temperature.
To evaluate the damping we consider the complex version of Equation (9):

$$
B_{c}^{*} \approx E_{s} I_{s}\left(1+\mathrm{i} 2 \zeta_{s}\right)+E_{a}^{\prime} A_{a} \beta h^{2}\left(1+\mathrm{i} \eta_{a}\right)
$$

In the above expression, the moment of inertia of the pavement has been neglected and the factor $\beta$ is taken as real. The damping of the composite section can be written as

$$
\zeta_{c}=\frac{1}{2} \frac{\operatorname{Im} B_{c}^{*}}{\operatorname{Re} B_{c}^{*}} \approx \frac{E_{s} I_{s} \zeta_{s}+E_{a}^{\prime} A_{a} \beta h^{2} \eta_{a} / 2}{E_{s} I_{s}+E_{a}^{\prime} A_{a} \beta h^{2}}
$$

The damping of the composite section is thus basically the stiffness-weighted mean of the damping of the structure and of the asphalt pavement.

Since the squared frequency is proportional to the stiffness we have

$$
\zeta_{c}=\frac{1}{2} \frac{\operatorname{Im} B_{c}^{*}}{\operatorname{Re} B_{c}^{*}} \approx \frac{f_{s}^{2} \zeta_{s}+\left(f_{c}^{2}-f_{s}^{2}\right) \eta_{a} / 2}{f_{c}^{2}}
$$

Using the relative frequency and writing explicitly the dependency on temperature, we find:

$$
\zeta_{c} \approx \frac{\zeta_{s}+\left[\varphi^{2}(T)-1\right] \eta_{a}(T) / 2}{\varphi^{2}(T)}
$$

The damping ratio of the fundamental mode of the timber bridge estimated according to Equation (14) is plotted in Figure 25 . The estimates compare fairly well with the finite element results, both for full and partial bond. However, the derivation makes some assumptions that are not true in every case. Equation (14) is thus not generally applicable but is presented here to explain the origin of the typical form of the damping curve. The form of the damping curve is basically determined by two competing factors, which depend on the temperature: the factor $\left[1-\varphi^{2}(T)\right]$ and the loss factor $\eta(T)$. The first factor decreases with temperature (see Figure 24) while the second factor increases (see Figure 6). The product thus yields the typical form with a maximum at intermediate temperatures.

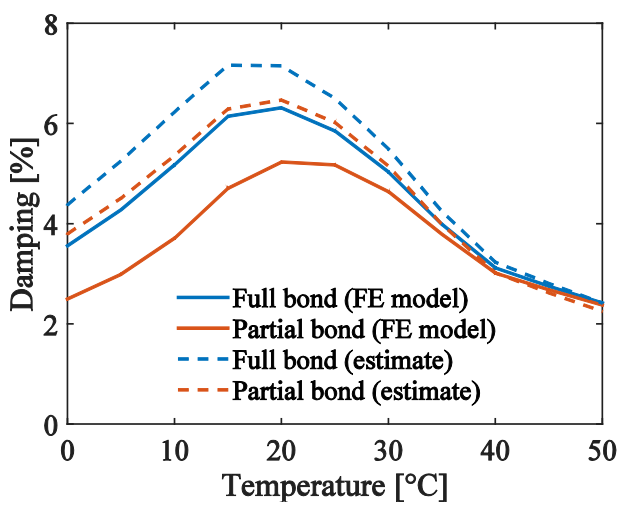

Figure 25. Damping ratios estimated from relative fundamental frequency of timber bridge. 


\section{Influence of supports}

\subsection{Friction in bearings}

The box girder steel bridge described above did not show a large sensitivity to temperature, but had another surprising behaviour. Before the asphalt pavement was applied, the bridge was on temporary bearings (Figure 26). The temporary bearings have no special previsions for movement in the longitudinal direction, but can take small displacements due to their flexibility. The measured natural frequencies without asphalt are shown in Table 2. Clearly the fundamental frequency is near the critical value of $2 \mathrm{~Hz}$ and one would expect large vibrations due to pedestrians. Nevertheless, the damping ratio was unexpectedly high due to friction developed in the temporary bearings, and the amplification of vibrations induced by pedestrians was limited. For welded steel structures, we normally expect a damping ratio of $0.3 \%$.

With the unusually thick asphalt pavement of $7.5 \mathrm{~cm}$, the fundamental frequency was expected to go down below a critical value of $1.6 \mathrm{~Hz}$. Nevertheless, the measurements showed a quite different value. As seen in Table 3, the fundamental frequency hardly went down, which was very surprising. The damping ratio went down, but only to $2 \%$, which is still much more than expected. The only reason for the unexpected behaviour could be the permanent bearings, which have been installed in the meantime. The permanent movable bearing is shown in Figure 27. This bearing has a sliding plate with PTFE surfacing for low friction and can move in the longitudinal direction. In the transverse direction, the movement is restricted by a guiding bar. It is suspected that the friction in the sliding plate was responsible for the observed behaviour.

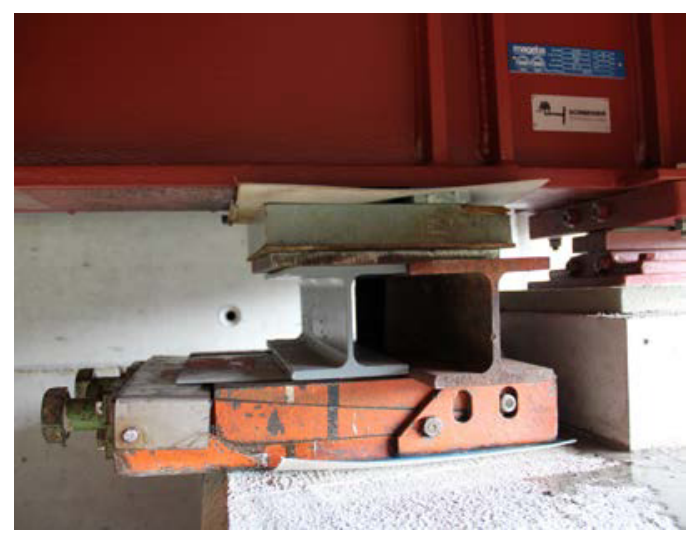

Figure 26. Temporary bearing of box girder bridge. View along bridge direction.

Table 2. Measured natural frequencies and damping ratios before installing the pavement.

\begin{tabular}{llll}
\hline Mode & Type & Frequency [Hz] & Damping [\%] \\
\hline B1 & Bending & 1.92 & 4.45 \\
\hline T1 & Torsion & 3.89 & 1.45 \\
\hline B2 & Bending & 6.39 & 0.25 \\
\hline
\end{tabular}

Table 3. Measured natural frequencies and damping ratios before and after installing the pavement.

\begin{tabular}{ll|ll|ll}
\hline & & \multicolumn{2}{|l|}{$\begin{array}{l}\text { Without pavement } \\
\text { temporary bearings }\end{array}$} & \multicolumn{2}{|l}{$\begin{array}{l}\text { With pavement } \\
\text { permanent bearings }\end{array}$} \\
\hline Mode & Type & $\begin{array}{l}\text { Freq. } \\
{[\mathrm{Hz}]}\end{array}$ & $\begin{array}{l}\text { Damp. } \\
{[\%]}\end{array}$ & $\begin{array}{l}\text { Freq. } \\
{[\mathrm{Hz}]}\end{array}$ & $\begin{array}{l}\text { Damp. } \\
{[\%]}\end{array}$ \\
\hline B1 & Bend. & 1.92 & 4.45 & 1.82 & 1.98 \\
\hline T1 & Torsion & 3.89 & 1.45 & 3.91 & 1.25 \\
\hline B2 & Bend. & 6.39 & 0.25 & 5.34 & 0.32 \\
\hline
\end{tabular}

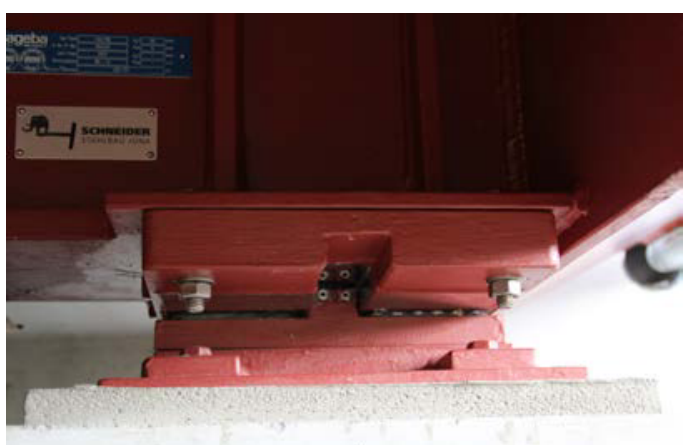

Figure 27. Permanent bearing of box girder bridge. View along bridge direction.

Table 4. Comparison of measured frequencies $[\mathrm{Hz}]$ with results from two FE models, before and after installing the pavement.

\begin{tabular}{l|ccc|ccc}
\hline & \multicolumn{3}{|l|}{ Without pavement } & \multicolumn{3}{l}{ With pavement } \\
& temporary bearings & \multicolumn{4}{c}{ permanent bearings } \\
\hline Mode & Meas. & Movable & Fixed & Meas. & Movable & Fixed \\
\hline B1 & 1.92 & 1.71 & 2.27 & 1.82 & 1.41 & 1.87 \\
\hline T1 & 3.89 & 3.90 & 4.19 & 3.91 & 3.65 & 3.94 \\
\hline B2 & 6.39 & 6.53 & 6.53 & 5.34 & 5.31 & 5.31 \\
\hline
\end{tabular}

The final explanation of the unexpected behaviour is provided by the finite element simulation. The bridge was modelled with shell elements. Two different support configurations were chosen. In one configuration, supports on both ends were pinned, whereas in the other configuration, supports at one end were freely movable in the longitudinal direction. The resulting frequencies are compared with the measured values in Table 4.

The comparison shows that, without pavement and with temporary bearings, the measured fundamental frequency (B1) lies between the two frequencies determined by the two models. This is intuitively plausible if we assume that the temporary bearings behave between fixed and free. More surprising are the results with pavement and permanent bearings. For the fundamental mode (B1), the permanent bearings act as if they were almost fixed instead of movable as designed. The same goes for the torsion mode (T1). For the second bending mode (B3), both models yield the same frequency close to the measured value. Support conditions have no influence in this case since this is an antisymmetric mode.

Despite the fact that the fundamental frequency of the final bridge is still in the critical range of 1.6-2.4 Hz, 
there is no problem with pedestrian-induced vibrations, since the damping ratio is still appreciable. Tests with one person jumping with a pace of $1.8 \mathrm{~Hz}$ lead to a peak acceleration of only $0.15 \mathrm{~m} / \mathrm{s}^{2}$, which is still below the recommended limit of $0.5-1.0 \mathrm{~m} / \mathrm{s}^{2}$. Although the bearings act like fixed supports, they probably still allow for some small movement and dissipate energy by friction.

\subsection{Elastic behaviour of supports}

Another case where the supports did not behave in ideal manner was observed with the truss steel bridge. While the first bending mode could be modelled by finite elements quite satisfactorily, the first torsion mode was difficult to match with measurements.

Since the elastomer bearings are stiff in the vertical direction but very flexible in the horizontal direction, they were modelled as vertically fixed and horizontally movable in the first models. Later on, the stiffness values taken from the manufacturer's specification were taken. Contrary to what has been expected, introducing a horizontal stiffness for the supports had an influence on the frequency of the torsion mode. To better understand this behavior, the influence of the horizontal stiffness of the supports has been investigated. For a very low horizontal stiffness, the bridge has three quasi-rigid body modes with low frequencies, followed by the structural modes. These mode shapes are shown in Figure 28.

Figure 29 shows the natural frequencies of the finite element model without asphalt. The quasi-rigid body modes, the first two bending modes, and the first torsion mode are plotted as function of the horizontal stiffness of the supports. As the stiffness increases, the frequencies of the quasi-rigid body modes increase and intersect the frequencies of the other modes. Since the horizontal and the vertical directions are uncoupled, the bending modes are not affected by the horizontal stiffness of the supports, whereas the torsion mode is coupled with the lateral mode.

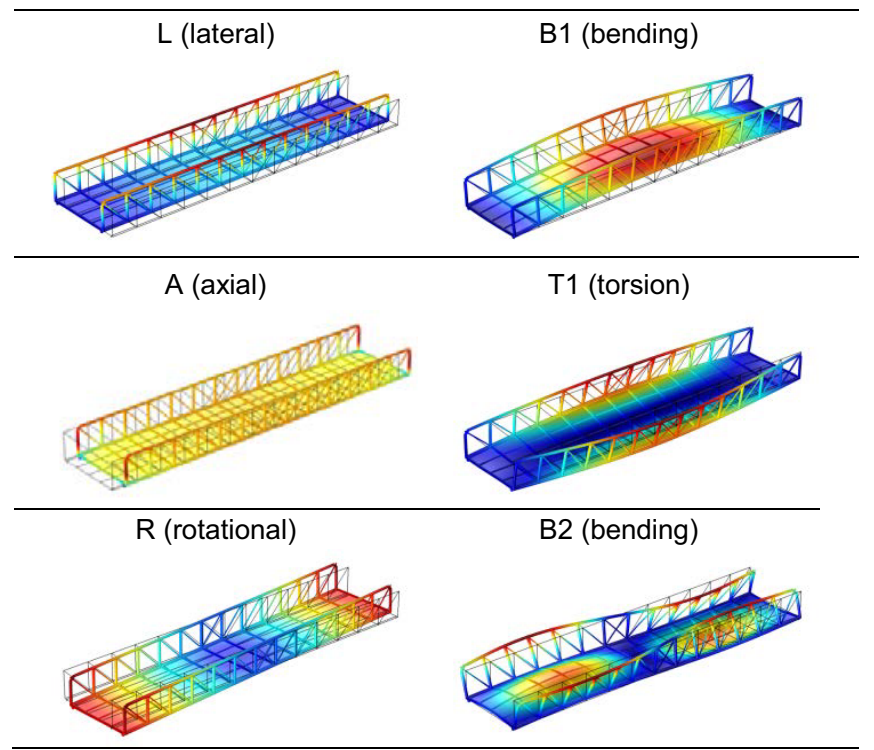

Figure 28. Mode shapes of truss bridge for low horizontal stiffness of supports.

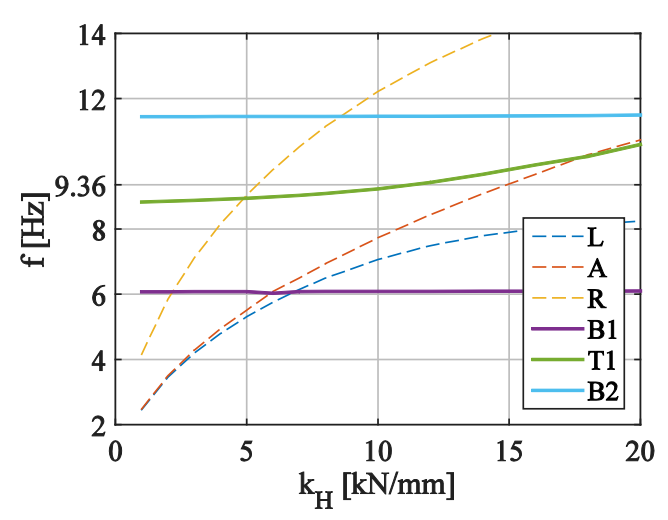

Figure 29. Natural frequencies of truss bridge without asphalt pavement in function of horizontal support stiffness.

The diagram in Figure 29 can be used for calibrating the horizontal stiffness of the bearings. The model matches the measured torsion frequency without asphalt pavement of $9.36 \mathrm{~Hz}$, if the support stiffness is around 12 $\mathrm{kN} / \mathrm{mm}$. The question remains, if this value corresponds to the real stiffness. According to the fact sheet provided by the manufacturer, the stiffness is only $1.12 \mathrm{kN} / \mathrm{mm}$. Consulting the manufacturer revealed that the numbers in the fact sheet are not coming from tests but are calculated from a code (DIN 1337-3). The calculated stiffness is based on static loading and on $100 \%$ shear deformation. For dynamic loading and small deformations, much higher values are expected. In this light, the value found from model calibration seems not to be unrealistic.

As a further verification of the horizontal support stiffness, a dynamic test of the bearing itself has been considered, but this turned out to be too expensive. As an alternative, horizontal vibration tests on the bridge were performed. The electromagnetic shaker was used in horizontal mode (Figure 30).

During these vibration tests, the asphalt pavement was already in place. Nevertheless, for the quasi-rigid modes, the asphalt temperature is not expected to be very influential. What could be important is the temperature of the elastomer bearings. Therefore, these temperatures were also recorded. However, since the bearings were not directly exposed to sunlight, their temperature only changed about $5^{\circ} \mathrm{C}$ during the day. During the tests, it was also observed that the bearings were distorted due to the thermal expansion of the bridge. It it assumed that the thermal expansion is mainly related to the temperature of the steel plate, which was measured by the thermoelements placed between the steel plate and the lower

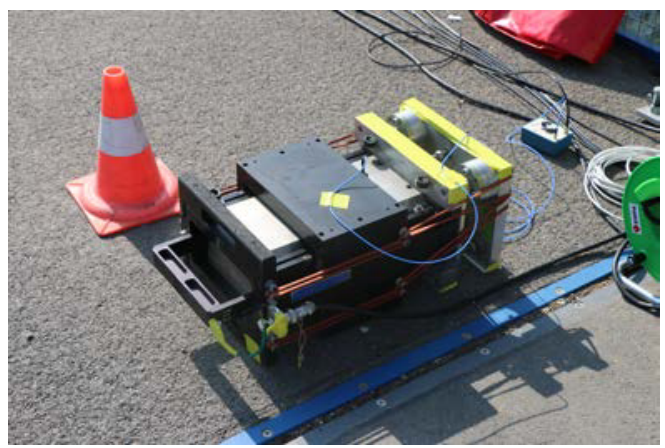

Figure 30. Shaker in horizontal mode. 


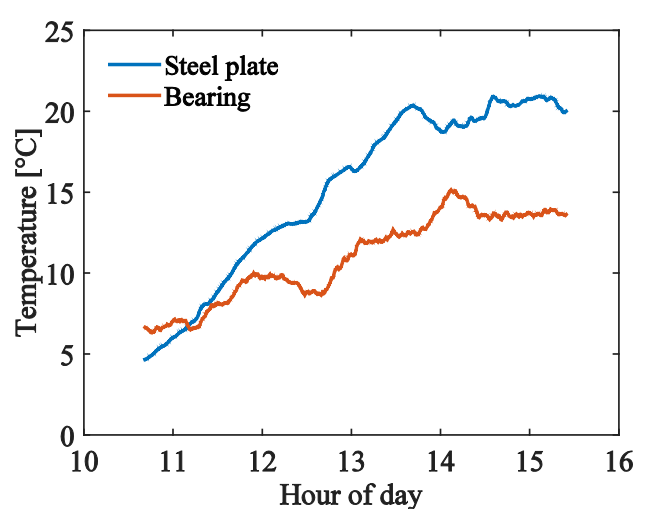

Figure 31. Temperatures of bearings and steel plate.

asphalt layer. The temperatures of the bearings and of the steel plate are shown in Figure 31.

Figure 32 shows the measured natural frequencies of the horizontal quasi-rigid modes in function of the temperature of the steel plate. For the lateral mode, this frequency is $5.8 \mathrm{~Hz}$ for lower temperatures but suddenly increases for temperatures above $20^{\circ} \mathrm{C}$. Similarly, the natural frequency for the rotational mode is $10.5 \mathrm{~Hz}$ for lower temperatures and increases for temperatures above $20^{\circ} \mathrm{C}$. It is supposed that the elongation of the bridge due to thermal expansion is compressing the expansion joints, which then add to the stiffness. A temperature dependence of the elastomer bearings would not explain the sudden increase of stiffness. On the contrary, a monotonic stiffness reduction would be expected.

Calculating the quasi-rigid modes with asphalt pavement at a temperature of $15^{\circ} \mathrm{C}$ in function of the horizontal support stiffness yields the curves plotted in Figure 33. Considering the lateral (L) measured frequency at $5.8 \mathrm{~Hz}$ and the rotational (R) measured frequency at $10.5 \mathrm{~Hz}$, the horizontal bearing stiffness is estimated to be around $10 \mathrm{kN} / \mathrm{mm}$ which is compatible with the earlier estimate of $12 \mathrm{kN} / \mathrm{mm}$. This confirms that the static value provided by the manufacturer cannot be used for the dynamic analysis.
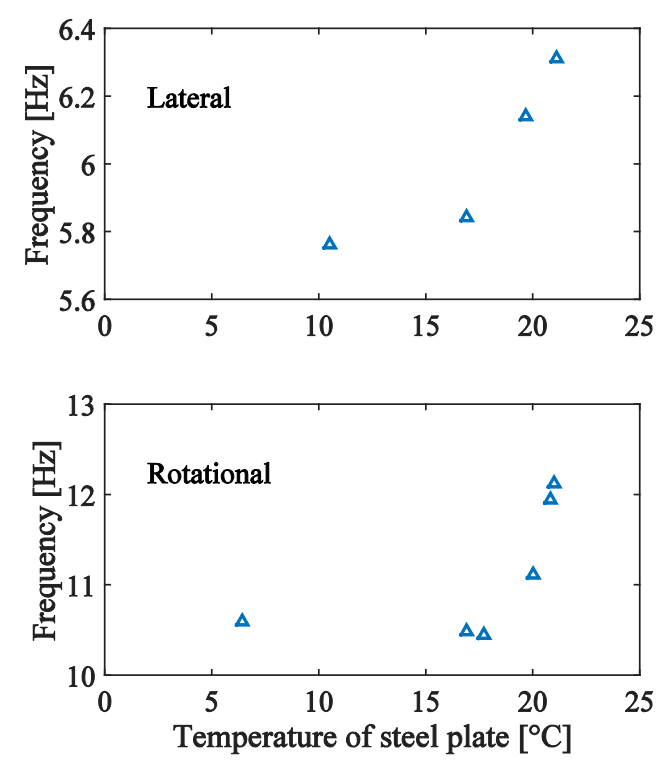

Figure 32. Measured natural frequencies of horizontal quasirigid modes.

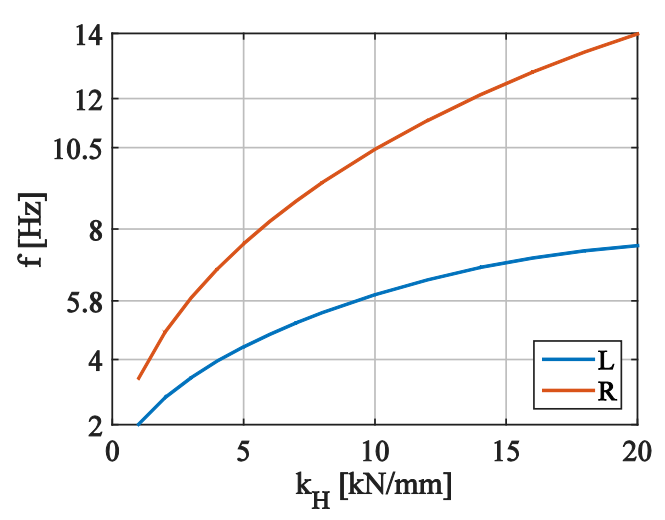

Figure 33. Natural frequencies of quasi-rigid modes in function of horizontal bearing stiffness with asphalt pavement.

\section{Conclusions}

Two non-structural elements have been identified which can significantly influence the dynamic properties of footbridges: the asphalt pavement and the supports.

Vibration tests on four footbridges showed a large variation of dynamic properties with the asphalt temperature. However, not all bridges were affected the same way. The influence of the asphalt pavement on different bridges can be mostly explained by considering the cross-section. The influence is the higher, the further away the pavement is form the neutral axis. However, other effects may play a role: (i) If the pavement is not fully bonded to the beam, the interface stiffness may reduce the effect. (ii) If the dynamic behaviour is not entirely governed by bending, e.g. in a cable-stayed bridge, the effect of asphalt is reduced. In the example, this saved the TMD from being detuned too much. (iii) Short bridges might vibrate more like a plate than like a beam. In this case, the cross-section might not fully describe the dynamic behaviour.

The influence of supports may lead to unexpected behaviour. It is known that friction in the bearings may change the boundary conditions from free to fixed. Nevertheless, if still some friction can be activated, this can increase the overall friction and the bridge might still fulfil the serviceability requirements, even if the frequency is quite different from the calculated value. Static design values for the stiffness of elastomer bearings provided by the manufacturer may significantly differ from real dynamic values.

\section{References}

[1] P. Hamm, "Ein Beitrag zum Schwingungs- und Dämpfungsverhalten von Fussgängerbrücken aus Holz”, TH München, München (2003) .

[2] A. Gülzow, R. Steiger, D. Gsell, W. Wilson, and G. Feltrin, "Dynamic field performance of a wooden trough bridge", in EVACES'07, 2nd International Conference on Experimental Vibration Analysis for Civil Engineering Structures 24-26 October 2007, Porto, Portugal. 
[3] S. Schubert, D. Gsell, R. Steiger, and G. Feltrin. "Influence of asphalt pavement on damping ratio and resonance frequencies of timber bridges", Engineering Structures, 32(10): 3122-3129 (2010).

[4] M. Ralbovsky, H. Friedel, und S. Wittmann, "Dynamic Behaviour of UHPFRC Arch Bridge Wild", in EVACES'11, Experimental Vibration Analysis for Civil Engineering Structures, 3-5 October 2011. Varenna, Italy: p. 693-700.

[5] H. Di Benedetto, B. Delaporte, and C. Sauzéat. "Three-dimensional linear behavior of bituminous materials: experiments and modeling", International Journal of Geomechanics, 7(2): 149-157 (2007).

[6] D. Ascher. "Untersuchungen zur Wirksamkeit des Haftverbundes und dessen Auswirkung auf die Lebensdauer von Asphaltbefestigungen", Institut für Stadtbauwesen und Verkehr, Technische Universität Dresden, Dresden (2007). 